This article was downloaded by:[AMS Fiocruz ENSP]

On: 19 October 2007

Access Details: [subscription number 731676317]

Publisher: Taylor \& Francis

Informa Ltd Registered in England and Wales Registered Number: 1072954

Registered office: Mortimer House, 37-41 Mortimer Street, London W1T 3JH, UK

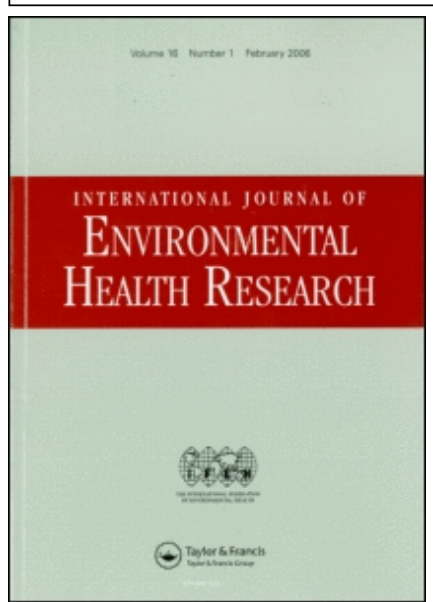

\title{
International Journal of Environmental Health Research
}

Publication details, including instructions for authors and subscription information: http://www.informaworld.com/smpp/title content=t713425582

Socio-environmental determinants of the leptospirosis outbreak of 1996 in western Rio de Janeiro: a geographical approach

Christovam Barcellos; Paulo Chagastelles Sabroza

Online Publication Date: 01 December 2000

To cite this Article: Barcellos, Christovam and Sabroza, Paulo Chagastelles (2000)

'Socio-environmental determinants of the leptospirosis outbreak of 1996 in western

Rio de Janeiro: a geographical approach', International Journal of Environmental

Health Research, 10:4, $301-313$

To link to this article: DOI: $10.1080 / 0960312002001500$

URL: http://dx.doi.org/10.1080/0960312002001500

\section{PLEASE SCROLL DOWN FOR ARTICLE}

Full terms and conditions of use: http://www.informaworld.com/terms-and-conditions-of-access.pdf

This article maybe used for research, teaching and private study purposes. Any substantial or systematic reproduction, re-distribution, re-selling, loan or sub-licensing, systematic supply or distribution in any form to anyone is expressly forbidden.

The publisher does not give any warranty express or implied or make any representation that the contents will be complete or accurate or up to date. The accuracy of any instructions, formulae and drug doses should be independently verified with primary sources. The publisher shall not be liable for any loss, actions, claims, proceedings, demand or costs or damages whatsoever or howsoever caused arising directly or indirectly in connection with or arising out of the use of this material. 


\title{
Socio-environmental determinants of the leptospirosis outbreak of 1996 in western Rio de Janeiro: a geographical approach
}

\author{
CHRISTOVAM BARCELLOS ${ }^{1}$ and PAULO CHAGASTELLES SABROZA ${ }^{2}$ \\ ${ }^{1}$ Department of Health Information Research, DIS/CICT/Fiocruz, Fundação Oswaldo Cruz, Brazil, ${ }^{2}$ Department of \\ Endemic Diseases 'Samuel Pessoa', National School of Public Health, Fundação Oswaldo Cruz, Brazil
}

\begin{abstract}
The environmental and social context in which a leptospirosis outbreak took place during the summer of 1996 in the Rio de Janeiro Western Region was examined by using spatial analysis of leptospirosis cases merged with population and environmental data in a Geographical Information System (GIS). Important differences were observed between places where residences of leptospirosis cases are concentrated and other places in the region. Water supply coverage, solid waste collection, sewerage system coverage and flood risk area were the main determining variables from an initial list of ten. The influence of these unfavorable social and environmental factors is verified hundreds of meters distant from the leptospirosis case residences, demonstrating a necessity to broaden the area of health surveillance practices. The geocoding indicated that some cases did not report contact with flood water, even though they were geographically adjacent to cases who did report this contact. Cases may only report exposures they believe are related to the disease. Geocoding is a useful tool for evaluating such bias in the exposure recall.
\end{abstract}

Keywords: floods; leptospirosis; GIS; sanitation; water-related diseases; disease foci; spatial analysis.

\section{Introduction}

Disease outbreaks are probably a result of a combination of social, environmental and individual variables, each laden with a brand of spatial expression. Several models have been proposed to identify the causal relationships between sanitation and health. The health indicators are affected by household conditions such as water supply, sewerage service and municipal waste collection, and also by individuals' characteristics such as habits and behavior (Kolsky and Blumenthal 1995). All these variables are influenced by the socioeconomic status (Heller 1997). Macroenvironmental conditions such as climate, land use and the presence of pollution sources compose the third group of variables that affect the overall population health. Therefore, the analysis of health risks presupposes the integration of data from different origins and its connection throughout different scales in which the socio-environmental phenomenon is manifested.

Since many variables predictive of life quality, health and environment are localizable in space, geoprocessing techniques are imposed as tools for data organization and analysis,

Correspondence: Christovam Barcellos. Tel.: + 5521 2901696; Fax: + 5521 2702668; E-mail: xris@fiocruz.br 
particularly through one of its components, the Geographical Information System (GIS) that derives its growing usage from three properties: the capacity to deal faithfully with complex cartographic information; a spatial base conceived in such a way that allows integrating objects to given attributes; and a set of analytic tools that are adjusted to spatial analysis (Maguirre $e t$ al. 1991). The use of geoprocessing techniques in health studies greatly help to formulate and evaluate hypotheses concerning spatial distribution of diseases and deaths, mainly through promptly issuing thematic maps. Another significant application of GIS is the linkage it allows between environmental and health data, i.e. between environmental conditions, population exposure and the associated effects on health (Croner et al. 1996).

Leptospirosis is an acute disease commonly affecting liver and kidneys. Rats, mainly Rattus norvegicus, and dogs are important leptospire urban reservoirs. The cases of leptospirosis can be considered as 'sentinel events' of unfavorable socio-environmental conditions (Rothwell et al. 1991; Aldrich and Leaverton 1993), evidencing a collapse of health and sanitation services and preventive programs. The human infection is a result of skin or oral contact with the leptospire in which contaminated water and animal excrement play an important role (Katz et al. 1991). Disease lethality can increase up to $20 \%$ if cases are not promptly diagnosed and treated (Benenson 1997). Leptospirosis is an endemic disease in Rio de Janeiro, Brazil, presenting a baseline incidence of 30-50 cases per year, i.e. around 1 case per 100,000 inhabitants (SMS 1997). Its latency frequently generates disease outbreaks, mainly after flood events (Lacaz et al. 1972, Ko et al. 1999) due to the high prevalence of infections among rodents as verified in city slums (Pereira and Andrade 1988). Therefore, this event evidences a sequence of environmental conditions, involving solid waste accumulation, the proliferation of rodents and the vulnerability to the floods. All these conditions are avoidable or controllable through public policies of health promotion and sanitation.

During February 1996 heavy precipitation occurred throughout Rio de Janeiro, inundating some city areas for several days. Around 1500 leptospirosis cases were reported during February and March in Rio de Janeiro. This was the largest epidemic in the city's history. The incidence of leptospirosis cases throughout the city is shown in Fig. 1. These cases were mainly concentrated in the western and southern lowlands of the city, where the rainwater from coastal basins concentrated. The western region of the city (highlighted by a dashed line in the map) accounted for 87 leptospirosis cases after the rainfall and was chosen for this study because of the increasing population settlement in an area lacking urban infrastructure.

In this work we describe the population distribution, sanitation, flooding and housing conditions of the city's western region, selecting among plausible variables for those which better discriminate places where leptospirosis cases occurred. Geoprocessing techniques were used to establish influence areas around places of residence of notified cases. This ecological and spatial approach aims to recover the characteristics of the place of exposure and to relate it to the infection risks, incorporating complementary environmental variables which are not available in individual based epidemiological studies (Gesler et al. 1997). Therefore, this geographical approach privileges the places where cases occur rather than single cases to be investigated.

\section{Methodology}

GIS was used to gather and analyze socio-environmental and epidemiological data, which constitute specific information layers in the system. The Health Administration of Rio de Janeiro conducted an investigation on leptospirosis cases. For this investigation a form containing 


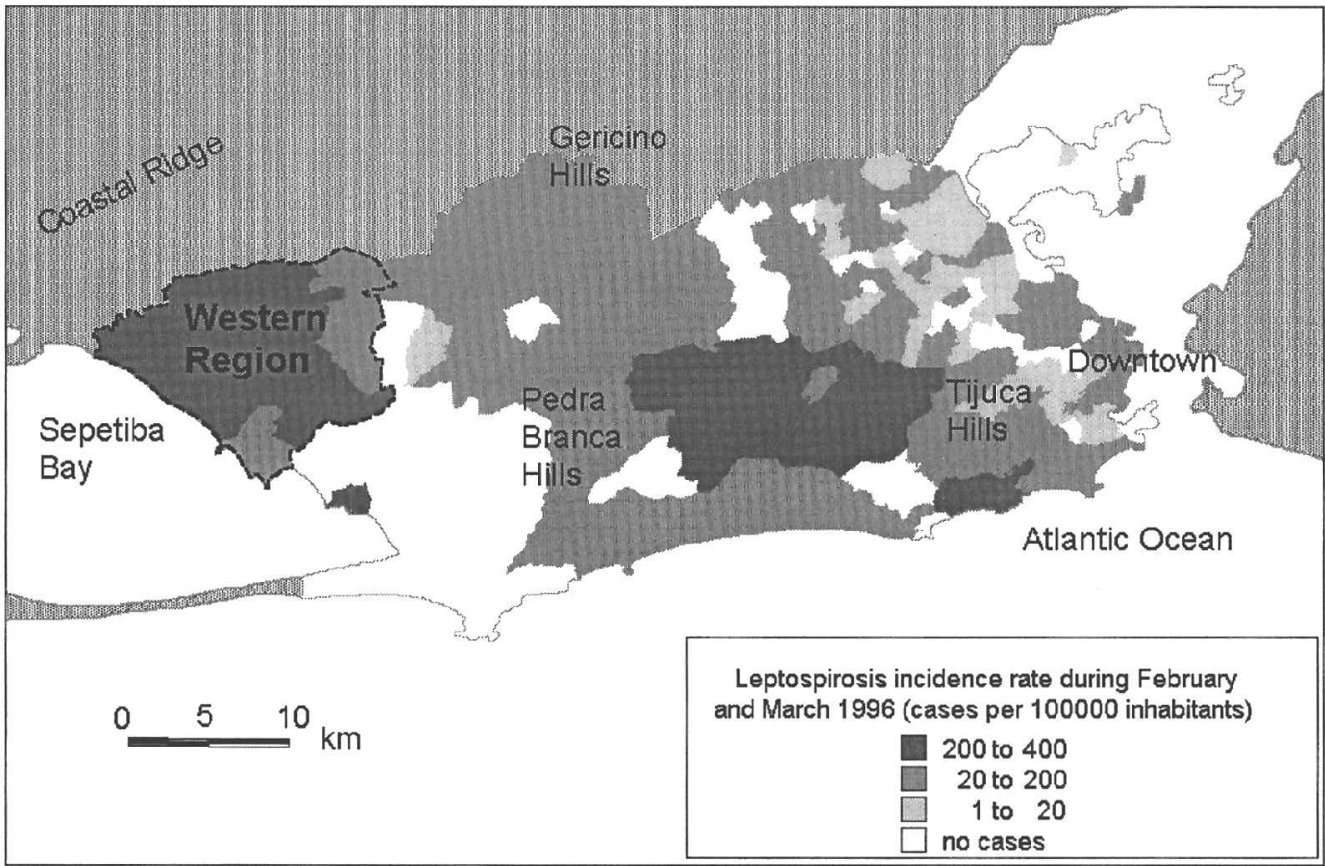

Fig. 1. Leptospirosis incidence rate in the city of Rio de Janeiro during the summer of 1996. Dashed line limits the Western Region (studied area).

personal data, address, characterization of exposure, clinical symptoms and treatment was completed. After the address check and elimination of duplicate cases from an initial list of 114 cases, 87 leptospirosis cases occurred in the Rio de Janeiro Western Region, between the 8th and 14th epidemiological week of 1996. This period corresponds to 4-41 days after the intensive rainfalls that started on February 13, and comprises the disease incubation period (Benenson 1997). The locations of notified case residences were obtained from the visual interpolation of street segments, using a recent city street guide and transcribed to a 1:5000 scale map, where coordinate pairs (UTM) were calculated. This procedure permitted the location of 73 residences. The remaining $16 \%$ of cases presented inconsistent address data, probably occurring among slum inhabitants and temporary residences.

Flood risk areas constitute a second information layer. This was obtained by digitizing areas (polygons) in which low terrain slope and rain water convergence increase the probability of flooding (Iplanrio 1995). The acquisition of the 276 census tract (CT) polygons involved the following steps: visual transcription of CT contour description to a 1:5000 scale map obtained from the local electric energy concessionaire (LIGHT); digitizing of the contours using a CADtype software; topology generation using ARC/INFO program; transportation of the polygons to Mapinfo format. Census data were obtained from the Brazilian Census Bureau (IBGE) and associated with CT polygons using a common code. Many socio-environmental indicators can be built from the census variables. The choice of indicators is determined according to the focus of the investigation and availability of data (Kolsky and Blumenthal 1995). In the present paper, urbanization patterns, income, sanitation and population distribution were used to characterize 
the region and the environmental conditions associated with leptospirosis. The following indicators of CT were built from the 1991 demographic census:

POP_RES: Average number of inhabitants per household in the CT. This variable can indicate housing internal conditions and overcrowding. Moreover, it is considered an indirect indicator of poverty.

L_DENS: Logarithm of the population density, calculated by the rate between the total population and the total area of the CT. The proximity among inhabitants allows the transmission of diseases and can hamper the appropriate elimination of human excreta.

P_WATER: Percentage of households supplied by the public water distribution system with internal water canalization. The absence of this service can promote the contamination of waters used for human consumption.

P_HOUSE: Percentage of houses in relation to the total number of residences of the CT. Indicates the degree of building verticalization, which can be related to the vulnerability to floods and to the presence of rodents in the household microenvironment.

P_SEWER: Percentage of households linked to sewerage systems with internal canalization. The existence of open sewage sinks and the presence of excreta inside the household can promote the local infestation by rodents. Also these conditions allow the direct or indirect contact with contaminated animal excreta.

P_SLUM: $\quad$ Percentage of household with slum characteristics, classified as 'sub-normal' or temporary by the IBGE. The slums possess, in general, lack of sanitation services besides concentrating low-income urban populations. Both factors can represent risks for the production of leptospirosis.

P_COLWAS: Percentage of households served by municipal solid waste collection. The absence of this service allows the accumulation of organic wastes, promoting the proliferation of rodents.

P_I2MW: $\quad$ Percentage of househeads with monthly income lower than two minimum wages. It has been used as a poverty indicator, and a probable access limiter to sanitation, health services and information.

POP_INC: Population increase rate in the CT between 1991 and 1996, when inundation occurred. The increase of population can aggravate urban infrastructure problems, favoring the exposure to contaminated materials.

The population increase between 1991 and 1996 was calculated based on the mid-decade census, after 1991 and 1996 CT polygons overlay in GIS environment. The other relevant variable was obtained from the overlay of CT with flood risk areas. The percentage of the CT area covered by flood risk polygons (P_FLOOD) was calculated in the CT worksheet by dividing the risk area contained in the $\mathrm{CT}$ by the total $\mathrm{CT}$ area.

The CT was used as the unit of analysis for socio-environmental and epidemiological data. The CTs located in the proximity to leptospirosis case residences were identified through the inter-relationship between the layer of cases and the layer of the CT. Influence areas, buffers around interest points (Croner et al. 1996), were drawn in concentric radius of 50, 100, 150, 200, 250, 300, 400, 500, 600, 800, 1000 and $1500 \mathrm{~m}$ around leptospirosis case residences. The CTs contained in each one of these influence areas were targeted in specific database fields conceived for bivariate statistical analysis of socio-environmental variables. Spatial operations 
were performed using Mapinfo GIS software (Mapinfo 1996). The socio-environmental conditions in the adjacent areas of leptospirosis cases were examined by comparing census tract variables within the influence area of case residences with the remaining CT, outside this area. In this sense, positive CT, where leptospirosis cases occur, were considered as 'cases', and negative CT were considered as 'controls'. The statistical significance of the difference of means between the two categories was examined through variance analysis (ANOVA method) using SPSS statistical software (SPSS 1993).

\section{Results and discussion}

The spatial distribution of the selected variables was analyzed by means of thematic maps. The observed patterns of socio-environmental indicators are summarized below. The total population of the Rio de Janeiro Western Region, as accounted by the 1996 census, was 275,000 inhabitants. The observed population distribution in the region shows two main urban nuclei: Santa Cruz and Sepetiba (Fig. 2). Peripheric areas in this part of the city present low population density, with similar values to rural zones. A considerable portion of the area is preserved due to the presence of mountain areas (north and east), military zones (south) or industrial poles (west), hampering the urban expansion in the region. The slum areas are mainly located to the north of Santa Cruz, along the railway and highways, where availability of lands and transport favors the occupation. The population living in slums is about 19,000 people, corresponding to 7\% of total inhabitants. A larger population increase between 1991 and 1996 was observed around the urban center of Santa Cruz. In the southern areas, the existence of marshes, mangroves and military zones hinders the settlement of new urban areas.

Rio de Janeiro Western Region has considerably lower incomes compared with the city as a whole. Inside the region, however, important social differentials are observed (Fig. 2(a)). According to census data there is a concentration of higher-income populations in Santa Cruz and Sepetiba centers. Pedra Branca hill includes low-income households associated with a remaining rural activity. Also, the northern area includes low-income populations, coinciding with the slum areas described above.

Most of the households in the urban areas area served by regular collection of municipal waste (Fig. 2(b)). The local population density often imposes restrictions for granting such a service, which is virtually absent in rural areas. Furthermore, slums have severe restrictions for waste collection. Sewage collection and treatment are considered severe sanitation issues in the Rio de Janeiro Metropolitan Area. Rio de janeiro Western Region has an incomplete sewer network with heterogeneous area coverage (Fig. 2(c)). In recent settlements, slums and semirural areas only a low fraction of households are served by the sewerage system. Peripheric and mountainous areas present difficulties in accessing of sanitation services, all of which are aggravated by the poor quality of water supply and absence of municipal waste collection. These factors are found to be strongly associated in space, i.e. poor areas tend to concentrate a lack of all services, whereas densely populated and rich areas benefit from a wide range of sanitation services. The associations between the various socio-environmental factors can be observed in Table 1.

The coverage of water supply, sewerage systems and municipal waste collection services have a positive and significant statistical correlation. This group of sanitation indicators is significantly associated with the population density of the CT. The presence of slums is negatively correlated with the coverage of sewerage and waste collection, indicating an absence of these services in slums. The low-income indicator is positively associated with the percentage 


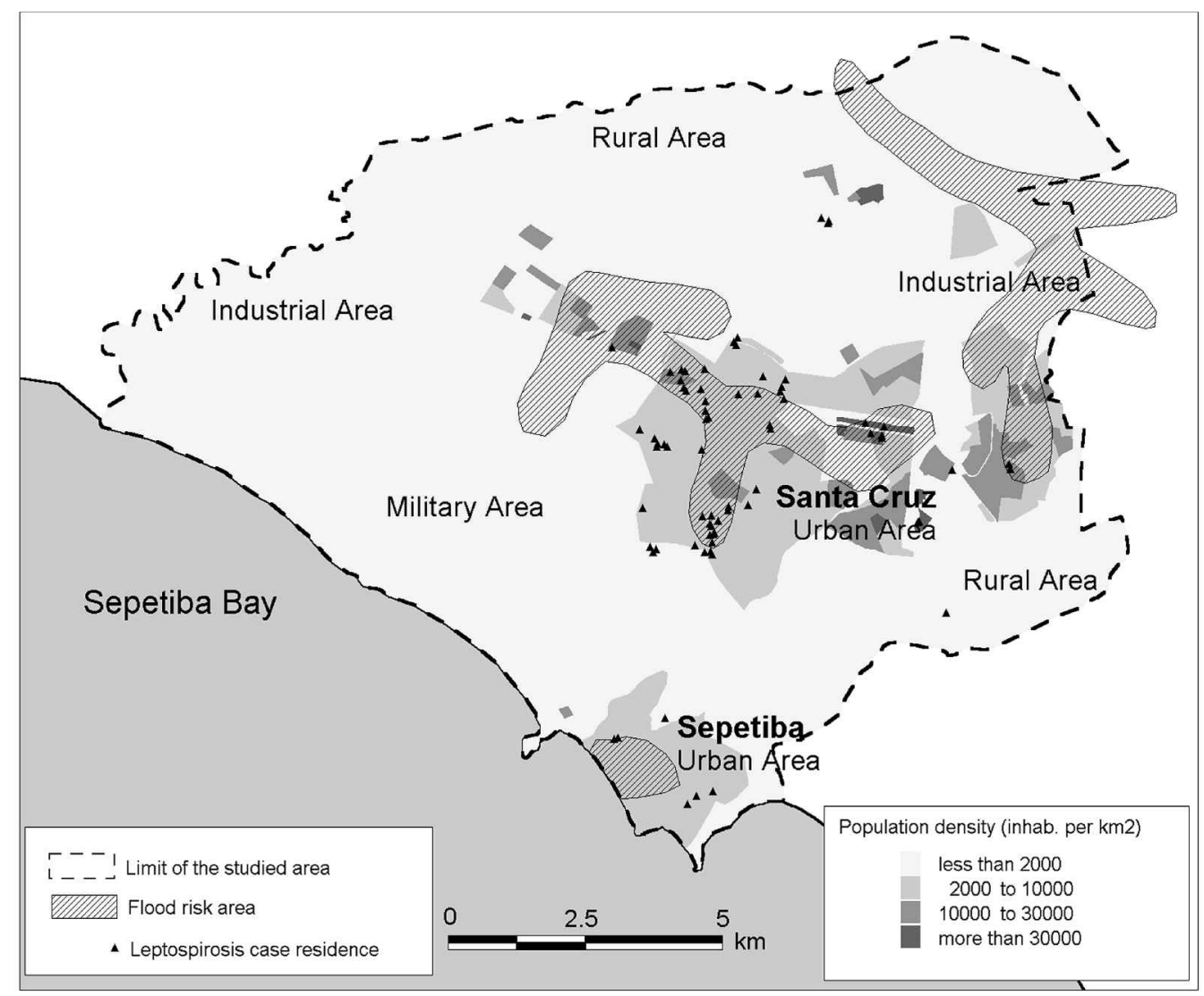

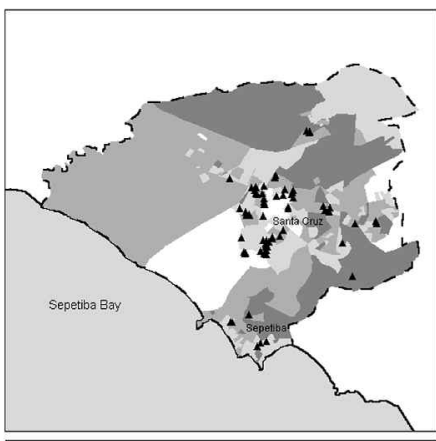

a) Proportion of low-income population
62 to $86 \%$
50 to $62 \%$
38 to $50 \%$
1 to $38 \%$

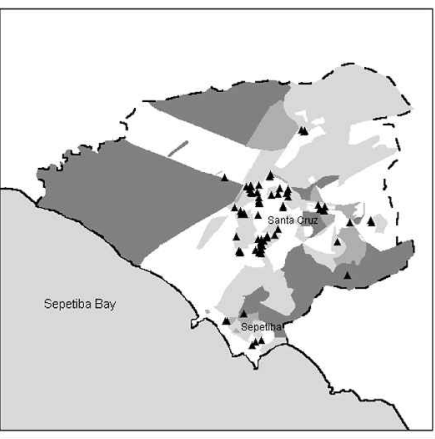

b) Solid waste collection

more than $80 \%$

50 to $80 \%$

2 to $50 \%$

less than $20 \%$

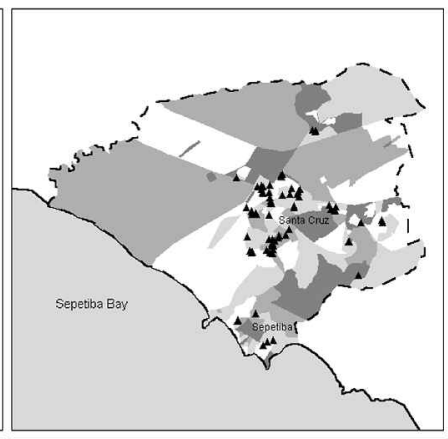

c) Sewerage coverage

more than $80 \%$

50 to $80 \%$

20 to $50 \%$

less than $20 \%$

Fig. 2. Location of leptospirosis case residences and population density in the Western Region of the city of Rio de Janeiro. Other socio-environmental characteristics (proportion of low-income population, sewerage coverage and solid waste collection) of the region are shown in the small frames. 


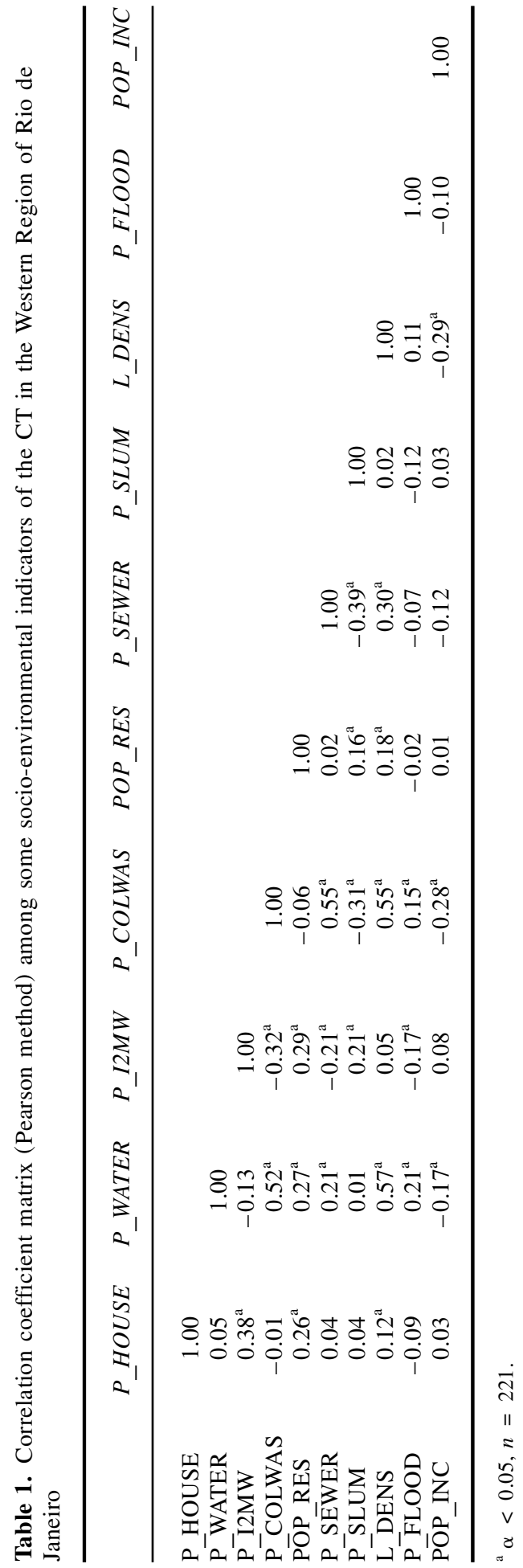


of the population living in slums, the average number of inhabitants per household and the percentage of houses in relation to the total CT households as well. Furthermore, low-income areas have lower coverage of sewer and municipal waste collection services. Flood areas mainly affect sectors of the region with good sanitation services. This pattern is evidenced by the positive association between flood risk area and water supply coverage, as well as with solid waste collections service, being negatively correlated to the low-income indicator. Population density is directly associated with the proportion of houses in the CT and the household crowding. Population increase between 1991 and 1996 is negatively associated with water supply and waste collection services and with population density. Previously unoccupied areas are being utilized by new urban settlements.

Georeferencing of leptospirosis cases allowed the identification of risk areas in a local scale. Deriving from the map it is observed the concentration of cases in Sepetiba and Santa Cruz centers. In these areas, the concentration of human and vector population, together with vulnerability to floods, form a susceptible scenario for leptospirosis outbreaks. On the contrary, cases are virtually absent on the hill and in rural areas. These areas are characterized by low population density, steep terrain and poor sanitation service coverage, which can represent a protection against waste accumulation and the human exposure to floodwater.

From the total of 87 cases, approximately 30\% declared during the investigation a recent contact with floodwaters. Cases who declared a contact with floodwaters were more frequently in the southern and western sectors of the region. These areas are recognized as being more vulnerable to floods due to the convergence of rivers, drainage canals and low slope terrain (Argento and Vieira 1988). On the other hand, cases who declared contact with floodwaters are sometimes adjacent to non-contact cases. It is likely that this exposure route involved almost the totality of cases, due to the local low altitude and the magnitude of the flood event. This apparent contradiction may constitute a bias of the investigation process. Psychosocial factors can influence people's perception on risk factors and exposure forms (Nurminen 1995). Cases may only report exposures they believe are related to the disease. Geocoding is a useful tool for evaluating such bias in the exposure recall. Only $22 \%$ of the investigated cases admitted to having had contact with rodents. The recognition of contact, when reported by infected people, may measure awareness rather than risky behavior (Childs et al. 1992). Since rodents only indirectly transmit the infectious agent, mainly through urine, the direct contact with rodents does not necessarily promote infection, nor, otherwise, the absence of this contact hinders infection. The environmental exposure assessment is, in such a case, impaired at individual level, since rodent and cases share a common environment with no direct contact with each other. From the information system point of view, infection is pertinent to the individual, whereas contamination is an attribute of the environment. GIS is helpful in promoting the integration of these different databases, which are related to different cartographic entities.

The continual transmission cycle of disease occurs only through an ill combination of individual conditions such as behavior, lifestyle, clinical history, susceptibility related to environmental and social macro-processes, such as environmental vulnerability, presence of contamination sources, existence of collective equipments and welfare measures enforcing health protection. Macro and micro variables are certainly correlated and from more than one combination among them derive the process of disease production (Diez-Roux 1998). Thus, ecological studies can provide information that is not perceived at the individual level (Susser 1994).

The socio-environmental determinants of the outbreak were examined by comparing the mean of the indicators of two categories of CTs: under the influence area of leptospirosis cases 
Table 2. Mean and standard deviation of selected indicators of census tracts within and outside a radius of $250 \mathrm{~m}$ around leptospirosis cases

$$
\begin{aligned}
& \text { Out of the } \\
& \text { influence } \\
& \text { area of cases }
\end{aligned}
$$

In the influence area of cases

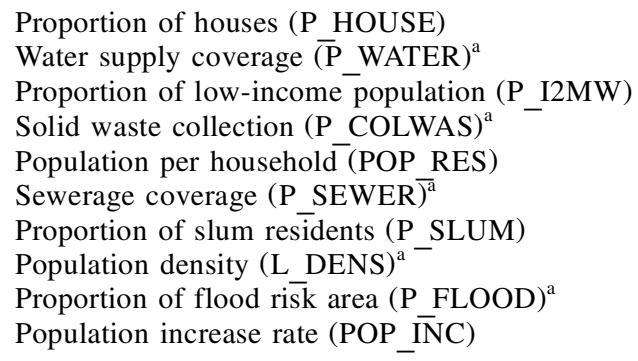

$0.97 \pm 0.08$

$0.96 \pm 0.08$

$0.51 \pm 0.11$

$0.89 \pm 0.21$

$3.92 \pm 0.35$

$0.70 \pm 0.37$

$0.15 \pm 0.34$

$3.88 \pm 0.61$

$0.26 \pm 0.38$

$6.17 \pm 22.2$
$0.96 \pm 0.08$

$0.91 \pm 0.14$

$0.52 \pm 0.13$

$0.75 \pm 0.27$

$3.90 \pm 0.37$

$0.55 \pm 0.32$

$0.11 \pm 0.30$

$3.63 \pm 0.72$

$0.39 \pm 0.42$

$6.28 \pm 27.4$

${ }^{\text {a }}$ Significant difference between means $(\alpha<0.05, n=221)$ according to ANOVA test.

and out of this influence area. This analysis was performed for a wide range of radius (from 50 to $1500 \mathrm{~m}$ ) around leptospirosis cases in order to evaluate the spatial range within which the influence of poor sanitation services and habitation characteristics is perceived. Table 2 shows the mean and standard deviation of variables of $\mathrm{CT}$ within a $250 \mathrm{~m}$ radius around cases. This range is used as an example of a medium distance between the case residence and the environmental and social conditions likely involved in the exposure to risk factors.

The CT located near leptospirosis cases differ from others due to the lower coverage of water supply, lower use of municipal waste collection and scarce sewerage services, higher presence of flood risk areas, together with a lower population density. Other variables, such as income, population increase and household crowding did not present significant difference among the CT.

Variance analysis, (ANOVA test) was applied for other influence radius (50-1500 m) using the presence of leptospirosis cases as categorical variable. Figure 3 indicates the distance interval between case and $\mathrm{CT}$ in which the variables present significant differences.

According to the figure an influence is observed of solid waste collection and water supply service deficiencies at short distances of the case residence site $(200-600 \mathrm{~m})$. Sewerage deficiencies are observed in a wider range, from 200 to $1000 \mathrm{~m}$. Flood risk areas are a common presence in a range between 50 and $800 \mathrm{~m}$ from leptospirosis case residences. The population density and the presence of houses present significant association with the existence of cases in more distant areas $(500-100 \mathrm{~m})$. The variables related to income, population increase and slum do not present significant difference in any distance range from the case. A first group of variables ( $\mathrm{P}$ _COLWAS, $\mathrm{P}_{-}$FLOOD and $\mathrm{P}_{-}$WATER) are paired correlated (see Table 1) and expresses environmental and urban infrastructure conditions. A second group of variables (P_HOUSE and POP_RES) affects larger distances from the case and summarizes residence internal conditions. Curiously, when comparing the $37 \mathrm{CT}$ s in which cases were exactly located (zero distance between cases and CT) with the remaining 239 CTs, where no leptospirosis cases were notified, no significant differences were observed between the areas. 


\begin{tabular}{|c|c|c|c|c|c|c|c|c|c|c|c|c|c|}
\hline $\begin{array}{l}\text { Distance between } \\
\text { case and CT (m) }\end{array}$ & 0 & 50 & 100 & 150 & 200 & 250 & 300 & 400 & 500 & 600 & 800 & 1000 & 1500 \\
\hline \multicolumn{14}{|l|}{ P_FLOOD } \\
\hline \multicolumn{14}{|l|}{ P_COLWAS } \\
\hline \multicolumn{14}{|l|}{ L_DENS } \\
\hline \multicolumn{14}{|l|}{ P_SEWER } \\
\hline \multicolumn{14}{|l|}{ P_WATER } \\
\hline \multicolumn{14}{|l|}{ P_HOUSE } \\
\hline POP_RES & & & & & & & & & & & & & \\
\hline
\end{tabular}

Fig. 3. Socio-spatial indicators that characterize the census tracts around leptospirosis case residences during the leptospirosis outbreak of 1996 in the Western Region of Rio de Janeiro.

The resultant scenario of leptospirosis place of occurrence is characterized by the proximity to deficient sanitation services and flood risk areas. The presence of slums, which are scattered over all the region, does not seem a likely component of this scenario. The verified distance lag between disease cluster and environmental risk factors can be explained by sort of immunological and environmental reasons.

First, leptospirosis cases during flood occasions may occur distant from the main disease foci due to immunologic individual protection of people living close to these foci. People living at distances further than $1500 \mathrm{~m}$ from foci are probably protected against rodents and infectious agents due to the limited dispersion capacity during the flood. Conversely, people living close to risk areas are supposed to have had contact with the infectious agent prior to the flood, acquiring immunity due to the proximity of suspected foci (Pavlowsky 1988). In this sense, slums can be considered as leptospirosis endemic areas. A survey performed in one of the lowland Rio de Janeiro slums demonstrated a serological prevalence as high as $25 \%$, with an infection rate of $1 \%$ per year (Pereira and Andrade 1990). In such cases, infection's are found to be related to occupational and behavior factors, presenting a typical endemic evolution pattern (Velazquez et al. 1984).

Second, the range between risk factors and case residence place may be an artifact produced by the errors involved in the location of geographical features in GIS. The average CT area is $0.28 \mathrm{~km}^{2}$, with an average radius of $290 \mathrm{~m}$. The location error of GPS equipments (Global Position System, a satellite-based coordinate acquirer) at this time was between 20 and $40 \mathrm{~m}$. The average length of street segments is $150 \mathrm{~m}$. As the notified case residences were located by interpolation in street segments, a maximum error of $75 \mathrm{~m}$ is expected for the coordinates of registers position. These distances are considerably longer than the linear resolution of the CT base map, which has an expected error of $2.5 \mathrm{~m}$. These values are related to the scale that was used to build the cartographic base. Each working scale induces a resolution limit that affects the statistical results obtained from the map. In this study, the distance in which poor sanitation services influences leptospirosis case location is considerably larger than georeferencing errors involved.

Finally, the contact between infectious agent and susceptible people can occur distant from the supposed foci or the case residence because of rodent and people movements, mainly in flood occasions. A redistribution of rodent population to higher ground is expected during flood, promoting a novel contact of disease agent with previously protected human population groups. As mentioned before, the flood persisted during several days and people may have been exposed 
to contaminated floodwater along the course to workplace and shopping, although living in a well served and non-inundated area. Unfortunately, GIS often considers a static representation of geographical entities, although space is composed of a system of objects and actions (Santos 1996).

Any of these reasons considered, the observed influence radius of poor sanitation services and flood areas allow the definition of leptospirosis risk areas beyond the case residence surroundings, which implies an enlargement of the scope of health surveillance activities.

\section{Final comments}

The case of leptospirosis is a good example of taking a disease and applying to it the concept of sentinel even as to encompass environmental and social vulnerabilities that will permit targeting of priorities. The Western Region of Rio de Janeiro, due to its diversity in the land use, is perhaps a model case of concentration of negative factors in areas and social groups. In mountainous areas, for instance, the low-income population is dispersed, with little or no access to the urban infrastructure. The low population density, on the other hand, allows for disposal of liquid and solid wastes with greater dilution, fortunately reducing the water-borne disease transmission risk. The areas with higher population density present risks to health derived from the accumulation of wastes that favor the proliferation of vectors and pathogenic microorganisms. Some dense urban areas, however, have individual and collective health protection measures, such as sanitation practices. Therefore, urbanization plays a double role of, on the one hand, promoting education and sanitation, and on the other hand, increasing interactions of infectious agent and population by overcrowding and pollution (Williams 1990).

The exposure to the infectious agents is an environmental and, therefore, collective process. The environmental conditions that produce diseases are impossible to be recalled through the sole aggregation of individual data, and should be obtained as well from bases addressing ecological variables (Vine et al. 1997, Diez-Roux 1998). Individual response is complementary and may be even divergent to environmental data. For instance, the data arising from investigation showed that most of the cases deny contact with solid waste, in spite of living near areas with deficient municipal waste collection. These areas are latent foci of diseases and, even when a residence presents appropriate practices of waste collection and disposal, the local infestation by rodents and canines can enlarge risks due to the presence of dumping areas in the neighborhoods. One of the important issues raised in this work is related to establishing the physical-territorial limits of these surroundings, which can be influenced by solid waste, rodent and bacteria actions.

Leptospirosis epidemics are produced by a combination of risk situations, involving sanitation, vectors, and human population and exposure route (in this case water) as well. These events and risk situations are not coincident in time and space. Case clusters take place some hundreds of meters from the presumed foci, evidencing a need to broaden the disease prevention actions around risk areas.

\section{Acknowledgements}

Epidemiological data were kindly provided by the State Health Secretary of Rio de Janeiro. Other field and cartographic information were gathered by Simone Santos and Fátima Pina. The 
authors would like to thank the useful collaboration of Celia Leitão Ramos and the anonymous referees in the review of the paper. This work was undertaken with the support of the Conselho Nacional de Desenvolvimento Científico e Tecnológico (CNPq).

\section{References}

Aldrich, T.M. and Leaverton, P.E. (1993) Sentinel event strategies in environmental health. Ann. Rev. Public Health 14, 205-217.

Argento, M.S.F. and Vieira, A.C. (1988) Impacto ambiental na Praia de Sepetiba. In Congresso Brasileiro de Sensoriamento Remoto (Proceedings), Natal (Brazil).

Benenson, A.S. (1997) Manual para el control de las enfermedades transmisibles. Washington: 16 ed. Organización Panamericana de Salud.

Childs, J.E., Schwartz, B.S., Ksiazek, T.G., Graham, R.R., Leduc, J.W. and Glass, G.E. (1992) Risk Factor associated with antibodies to leptospires in inner-city residents of Baltimore: a protective role for the cats. Am. J. Public Health 82, 597-599.

Croner, C.M., Sperling, J. and Broome, F.R. (1996) Geographic information systems (GIS): new perspectives in understanding human health and environmental relationships. Statistics Med. 15, 1961-1977.

Diez-Roux, A.V. (1998) Bringing context back into epidemiology: variables and multilevel analysis. Am. J. Public Health 88, 216-222.

Gesler, W.M., Bird, S.T. and Oljeski, A.S. (1997) Disease ecology and a reformist alternative: the case of infant mortality. Social Sci. Med. 44(5), 657-671.

Heller, L. (1997) Saneamentoe e Saúde. Brasília: Organização Panamericana de Saúde.

Iplanrio (1995) Anuário estatístico da cidade do Rio de Janeiro. Rio de Janeiro: Empresa Municipal de Informática e Planejamento.

Katz, A.R., Manea, S.J. and Sasaki, D.M. (1991) Leptospirosis on Kauai: investigation of a common source of waterborne outbreak. Am. J. Public Health 81, 1310-1312.

Ko, A.I., Galvao Reis, M., Ribeiro-Dourado, C.M., Johnson, W.D. and Riley, L.W. (1999) Urban epidemic of severe leptospirosis in Brazil. Lancet 354 (9181), 820-825.

Kolsky, P.J. and Blumenthal, U.J. (1995) Environmental health indicators and sanitation-related disease in developing countries: limitations to the use of routine data. World Health Statistic $Q$. 48, $132-139$.

Lacaz, C.S., Baruzzi, R.G. and Siqueira Junior, W. (1972) Introdução à Geografia Médica do Brasil. São Paulo: Edgard Blucher.

Maguirre, D.J., Goodchild, M.F. and Rhind, D.W. (1991) Geographical Information Systems: Principles and Applications. London: Longman.

Mapinfo (1996) Mapinfo Reference, Release 4.0. New York: Mapinfo Corporation.

Nurminen, M. (1995) Linkage failures in ecological studies. World Health Statistic Q. 48, 78-84.

Pavlovsky, E. (1988) Natural nidality of transmissible disease in relation to landscape epidemiology of zooanthroponoeses. In The Challenge of Epidemiology, Scientific Publication No. 505, pp. 401-405. Washington: Panamerican Health Organization.

Pereira, M.M. and Andrade, J. (1988) Epidemiological aspects of leptospirosis in a slum area in the city Rio de Janeiro, Brazil. Search for leptospirosis and specific antibodies in rodents. Trans. R. Soc. Tropical Med. Hyg. 82, 768-770.

Pereira, M.M. and Andrade, J. (1990) Human leptospirosis in a slum area in the city Rio de Janeiro, Brazil - a serological and epidemiological study. Mem. Inst. Oswaldo Cruz 85(1), 47-52.

Rothwell, C.J., Hamilton, C.B. and Leaverton, P.E. (1991) Identification of sentinel health events as indicators of environmental contamination. Environ. Health Perspect. 94, 261-263.

Santos, M. (1996) Técnica, espaço, tempo. São Paulo: Hucitec.

SMS (1997) Série histórica da Leptospirose no Rio de Janeiro (Technical report). Rio de Janeiro: Secretaria Municipal de Saúde, Superintendéncia de Saúde Coletiva. 
SPSS (1993) Base System Syntax Reference Guide, Release 6.0. Chicago: SPSS Inc.

Susser, M. (1994) The logic in ecological: I. The logic of analysis. Am. J. Public Health 84, 825-829.

Velazquez, J.Z., Cantarell, K.P., Castillo, M.F. and Centeno, A.G.D. (1984) Laleptospirosis en Yucatán. Estudio serológico en humanos Y animales. Salud Publica Mexico 26(3), 254-259.

Vine, M.F., Degnan, D. and Hanchette, C. (1997) Geographic information systems: their use in environmental epidemiologic research. Environ. Health Perspect. 105(6), 598-605.

Williams, B.T. (1990) Assessing the health impact of urbanization. World Health Statistics Q. 43, $145-152$. 